\title{
Apoptosis of bovine ovarian surface epithelial cells by Fas antigen/Fas ligand signaling
}

\author{
Kate A Margalit, Robert G Cowan, Rebecca M Harman and Susan M Quirk \\ Department of Animal Science, Cornell University, Ithaca, New York, USA \\ Correspondence should be addressed to S M Quirk, Department of Animal Science, 257 Morrison Hall, Cornell University, \\ Ithaca, NY 14853, USA; Email: smq1@cornell.edu
}

\begin{abstract}
Ovarian surface epithelial cells (OSEs), a single layer of cells that cover the surface of the ovary, undergo turnover at the site of follicular rupture at ovulation. Greater than $\mathbf{9 0} \%$ of ovarian cancers arise from the OSEs. The objective of this study was to determine whether OSEs have the capacity to regulate their own demise through expression of Fas antigen (Fas) and Fas ligand (FasL) and activation of Fas-mediated apoptosis. In initial experiments, primary cultures of bovine OSEs responded to treatment with recombinant FasL by undergoing apoptosis. The percentage of cell death was not affected by the presence or absence of serum in the media or by co-treatment with interferon- $\gamma$, a treatment shown to potentiate Fas-mediated apoptosis in a number of cell types. Subsequent experiments tested the ability of stress-inducing drugs, anisomycin and daunorubicin, to promote apoptosis by stimulating an endogenous Fas-FasL pathway in OSEs. Treatment with FasL, anisomycin or daunorubicin induced cell death and this was suppressed by co-treatment with a peptide inhibitor of caspases, ZVAD. Treatment with anisomycin or daunorubicin in the presence of ZVAD increased expression of FasL mRNA and protein but did not alter expression of Fas mRNA or protein. Treatment of OSEs with a recombinant protein that blocks interaction of FasL with Fas (Fas:Fc) reduced apoptosis in response to anisomycin and daunorubicin, indicating that drug-induced apoptosis was mediated at least partially through endogenous Fas-FasL interactions. In summary, OSEs undergo apoptosis in response to stress-inducing drugs through activation of an endogenous Fas pathway.

Reproduction (2005) 130 751-758
\end{abstract}

\section{Introduction}

Ovarian surface epithelial cells (OSEs) are a single layer of cells that surround the outer surface of the ovary in mammals. Prior to ovulation, OSEs overlying the site of follicular rupture degenerate by apoptosis (Talbot et al. 1987, Murdoch 1995). Regulation of apoptosis in OSEs is not completely understood. Characterizing the pathways that regulate the turnover of OSEs is important for understanding both the ovulatory process as well as processes whereby OSEs undergo transformation into cancerous cells (Murdoch \& McDonnel 2002). Indeed, greater than $90 \%$ of ovarian cancers are derived from OSEs. The cellsurface receptor Fas mediates apoptosis in many cell types (reviewed by Hengartner 2000). Fas is activated when bound by Fas ligand (FasL) under physiological conditions that promote apoptosis. Healthy cells, under the influence of the appropriate survival pathways, may be resistant to Fas-mediated apoptosis even when both Fas and FasL are available, while cells exposed to various stresses are susceptible, and Fas-FasL interaction results in apoptosis
(Porter et al. 2000, Quirk et al. 2000, 2004, Hu et al. 2001).

Previous studies in our laboratory showed that primary cultures of mouse OSEs express Fas and, under certain conditions, undergo apoptosis in response to an anti-Fas antibody that mimics FasL (Quirk et al. 1997). Whereas mouse OSEs cultured in serum-containing media were resistant to apoptosis in response to treatment with antiFas antibody, pretreatment with the cytokine interferon- $\gamma$ (IFN- $\gamma$ ) induced their susceptibility to apoptosis (Quirk et al. 1997). The ability of IFN- $\gamma$ to promote Fas-mediated apoptosis is consistent with findings in a variety of cell types (reviewed by Quirk et al. 1997, 2000). The expression of FasL in normal OSEs, and how expression may be regulated, has not been studied systematically. We hypothesized that healthy OSEs, cultured under conditions which support survival, do not express Fas and FasL simultaneously. Furthermore, FasL expression might be induced in OSEs subjected to stress and result in Fas-mediated apoptosis. In the experiments reported here, OSEs isolated from bovine ovaries were treated with drugs known to 
induce a stress response to determine whether OSEs have the ability to respond by expressing FasL and undergoing apoptosis through an endogenous Fas pathway. The drugs, anisomycin and daunorubicin, were tested because they are known to activate the c-Jun $\mathrm{N}$-terminal kinase (JNK) pathway and the mitogen-activated protein kinase (MAPK) p38 (Faris et al. 1998, Hsu et al. 1999, Mansat-De Mas et al. 1999). JNK and p38 MAPK pathways are activated predominantly by stress stimuli and may mediate apoptosis (reviewed by Leppã \& Bohmann 1999). For example, anisomycin was shown to induce apoptosis of Jurkat T cells by stimulating expression of FasL (Faris et al. 1998). However, JNK and p38 MAPK also stimulate diametrically opposed effects such as proliferation and survival depending upon the cellular context (reviewed by Leppã \& Bohmann 1999). Bovine OSEs were used in the current study because they can be readily isolated from abattoir material to generate highly enriched cultures of proliferative cells. Furthermore, the roles of various growth factors in stimulating the proliferation of bovine OSEs and comparisons of the characteristics of bovine and human OSEs have been reported (Doraiswamy et al. 2000, Parrott et al. 2000a, 2000b, Parrott \& Skinner 2000). Use of primary cultures of OSEs was desirable because these cells should reflect the function of normal OSEs more accurately than transformed or cancer cell lines. The results of this study indicate that expression of Fas does not change in response to drug-induced stress. In contrast, expression of FasL is low to non-detectable under control conditions and increases in response to stress. Endogenous Fas-FasL interactions then promote apoptosis.

\section{Materials and Methods}

\section{Materials}

Culture media and additives were obtained from Life Technologies (Grand Island, NY, USA) unless otherwise indicated. Murine epidermal growth factor (EGF) was from Invitrogen (Carlsbad, CA, USA). BSA, sodium pyruvate, L-glutamate, monoclonal anti-cytokeratin, normal goat serum (NGS), and mouse immunoglobulin $M$ (IgM) were from Sigma Chemical Company (St Louis, MO, USA). Tissue culture plates were obtained from Corning-Costar (Cambridge, MA, USA), except Slide-well chambers which were obtained from Nunc-Intermed (Naperville, IL, USA). Polyclonal rabbit anti-rat FasL antibody (IgG; antibody C-178) was obtained from Santa Cruz Biotechnology (Santa Cruz, CA, USA). Soluble recombinant human FasL and monoclonal mouse anti-human Fas antibody (IgM; clone $\mathrm{CH}$-11) were from Upstate Biotechnology (Lake Placid, NY, USA). Human Fas:immunoglobulin FC (Fas:FC) was from Pharmingen (San Diego, CA, USA). Rabbit IgG, Cy 2-conjugated donkey anti-mouse IgG, and normal donkey serum (NDS) were from Jackson ImmunoResearch Laboratories (West Grove, PA, USA). Alexa 488-conjugated goat anti-rabbit IgG and Alexa 488-conjugated goat anti-mouse IgG were from Molecular Probes (Eugene, OR, USA). Avian myeloblastosis virus reverse transcriptase (AMV-RT) and Access reverse transcriptase (RT) PCR reagents were obtained from Promega (Madison, WI, USA). Random hexamer was from Pharmacia (Piscataway, NJ, USA) and Taq polymerase was from Eppendorf (Westbury, NY, USA). Daunorubicin, anisomycin, and the interleukin-1 $\beta$-converting enzyme inhibitor Z-Val-Ala-DLAsp-fluoromethylketone (ZVAD) were obtained from Alexis Biochemical (San Diego, CA, USA). Bovine IFN- $\gamma$ was graciously provided by Dr Dale Godson (Veterinary Infectious Disease Organization, Saskatoon, SK, Canada).

\section{Cell culture}

Two culture media were used. OSE growth medium (OSEGM) contained Dulbecco's modified Eagle's medium (DMEM)/Ham's F12 (DMEM/F12), 5\% fetal bovine serum, $5 \mu \mathrm{g} / \mathrm{ml}$ insulin, $5 \mu \mathrm{g} / \mathrm{ml}$ transferrin, $20 \mathrm{nM}$ sodium selenite, $10 \mathrm{ng} / \mathrm{ml}$ EGF, $1 \mathrm{mM}$ pyruvate, $2 \mathrm{mM}$ glutamate, $100 \mathrm{U} / \mathrm{ml}$ penicillin, $100 \mu \mathrm{g} / \mathrm{ml}$ streptomycin, and $0.25 \mu \mathrm{g} / \mathrm{ml}$ fungizone. Minimal medium contained DMEM-F12 plus $100 \mathrm{U} / \mathrm{ml}$ penicillin, $100 \mu \mathrm{g} / \mathrm{ml}$ streptomycin, and $0.25 \mu \mathrm{g} / \mathrm{ml}$ fungizone. Freshly excised ovaries were obtained from an abattoir, transported in saline on ice, and processed within $3 \mathrm{~h}$. The surface of the ovary was gently scraped into OSEGM with a rubber policeman. Cells were rinsed and plated in OSEGM in $35 \mathrm{~mm}$ wells at a concentration of $1 \times 10^{6}$ cells/well. Large patches of OSEs grew to confluence within 5-10 days but were interspersed with areas of contaminating cells including stromal cells and fibroblasts. Areas that appeared to be pure OSEs, lacking cells with fibroblastic appearance, were isolated using trypsinization within a $6-\mathrm{mm}$ cloning cylinder and placed in a $35 \mathrm{~mm}$ culture dish (passage 1). After continued growth to confluence in OSEGM, the medium was changed to minimal medium. OSEs ceased to proliferate in minimal medium but did not die. Under these culture conditions, any contaminating fibroblasts or stromal cells that might be present would be unlikely to survive. Cells were maintained in minimal medium for 7-14 days and were passed by trypsinization (passage 2). For subsequent passages, cells were grown in growth medium and passed by trypsinization. All experiments were performed using cells from passages 3 or 4 . It was assumed that passage-3 and -4 cultures are reflective of the original cells collected, but this was not ascertained directly.

\section{Cell-viability assays}

OSEs were plated in OSEGM at the third passage in 96well plates $\left(4 \times 10^{4}\right.$ cells/well), grown to confluence (1-2 days) and, except where indicated, medium was changed to minimal medium. Then, 1 day later, indicated treatments were applied with a media change, and after $24 \mathrm{~h}$ cultures were trypsinized and live cells 
counted in a hemacytometer using the Trypan Blueexclusion method. The doses of FasL $(100 \mathrm{ng} / \mathrm{ml})$, anisomycin $(2 \mu \mathrm{M})$, and daunorubicin $(10 \mu \mathrm{M})$ used in all experiments were based on preliminary tests that determined the doses required to induce death of approximately $50 \%$ of cells in cultures of OSEs. IFN- $\gamma$ was used at a dose of $200 \mathrm{U} / \mathrm{ml}$ because this dose was shown to be maximally effective to promote Fasmediated apoptosis of mouse OSEs (Quirk et al. 1997) and to promote FasL-induced apoptosis of bovine granulosa cells (Vickers et al. 2000). ZVAD was utilized at a dose of $30 \mu \mathrm{M}$ as recommended by the supplier. Fas:Fc was used at $20 \mu \mathrm{g} / \mathrm{ml}$, a dose shown to suppress Fas-mediated apoptosis of bovine granulosa cells ( $\mathrm{Hu}$ et al. 2001). In each experiment, cells were counted from three wells for each treatment, and all experiments were repeated three times using different OSE preparations.

\section{Analysis of Fas and FasL mRNA by RT-PCR}

Fas and FasL mRNA were quantified by competitive RT-PCR as described previously (Vickers et al. 2000, Porter et al. 2001). At passages 3 or 4 , cells were plated in sixwell plates $\left(2 \times 10^{6}\right.$ cells/well $)$ and treated as described above for cell-viability assays. Twenty-four hours after treatment, cells were frozen at $-80^{\circ} \mathrm{C}$ for subsequent preparation of RNA. RNA was prepared (Chomczynski \& Sacchi 1987) and reverse transcribed in the presence of increasing concentrations of an internal Fas or FasL RNA standard. The Fas and FasL RNA standards were prepared by in vitro transcription of mutated Fas or FasL CDNA, each containing a $50 \mathrm{bp}$ deletion internal to the PCR primer-binding sites (described in Vickers et al. 2000, Porter et al. 2001). Complementary DNA was amplified by PCR in the presence of $\left[{ }^{32} \mathrm{P}\right] \mathrm{dCTP}$. PCR primers for Fas (positions 468-490 and 654-673 in GenBank accession no. NM_174662) were designed to span the positions of three introns and to generate a $256 \mathrm{bp}$ fragment from sample RNA and a 206 bp fragment from the internal RNA standard. PCR primers for FasL (positions 545-565 and 784811 in GenBank accession no. XM_584322) were designed to span the positions of two introns and to generate a $267 \mathrm{bp}$ fragment from sample RNA and a $217 \mathrm{bp}$ fragment from the internal RNA standard. RT-PCR for FasL was performed using an Access RT-PCR kit, which allowed increased sensitivity necessary to detect the relatively low amounts of FasL mRNA ( $<1 \mathrm{amol} / \mu \mathrm{g}$ RNA) present in the samples. PCR products were separated on an agarose gel, and the radioactive intensity of sample and standard bands determined by phosphorimaging. Sample mRNA concentration was calculated from the linear regression of standard concentration versus the ratio of sample intensity to standard intensity (Vickers et al. 2000). The between-assay coefficient of variation, based on a pooled RNA sample tested in every assay, was $9.1 \%$ for Fas and $14.7 \%$ for FasL ( $n=3$ each).

\section{Immunocytochemistry}

Expression of Fas, FasL, and cytokeratin proteins in cultured OSEs were examined by fluorescence immunocytochemistry as described previously (Hu et al. 2001). OSEs were plated at passage 3 in eight-well Slide-well chambers $\left(1 \times 10^{5}\right.$ cells/well), treated as described above for cell-viability assays, and fixed for immunocytochemistry $24 \mathrm{~h}$ after treatment. Cells were fixed in acetone, blocked with $\mathrm{PBS} / 2 \%$ NDS (Fas) or NGS (FasL and cytokeratin), rinsed, and incubated with the appropriate primary antibody $(2.5 \mu \mathrm{g} / \mathrm{ml}$ mouse anti-Fas IgM $2.5 \mu \mathrm{g} / \mathrm{ml}$ rabbit anti-FasL $\operatorname{lgG}$, or $1: 200$ anti-cytokeratin) in $\mathrm{PBS} / 2 \%$ BSA for $1 \mathrm{~h}$ at $37^{\circ} \mathrm{C}$. Some wells received normal $\lg \mathrm{G}$ of the appropriate species to determine background staining. Slides were rinsed and incubated with secondary antibodies in PBS $/ 2 \%$ BSA for $1 \mathrm{~h}$ at $37^{\circ} \mathrm{C}(0.75 \mu \mathrm{g} / \mathrm{ml} \mathrm{Cy2-conjugated} \mathrm{donkey}$ anti-mouse IgG for Fas, $2 \mu \mathrm{g} / \mathrm{ml}$ Alexa488-conjugated goat anti-rabbit IgG for FasL, or $1 \mu \mathrm{g} / \mathrm{ml}$ Alexa488-conjugated goat anti-mouse IgG for cytokeratin). Slides were observed under epifluorescent illumination using a $550 \pm 20 \mathrm{~nm}$ excitation filter, $580 \mathrm{~nm}$ dichroic mirror, and $590 \mathrm{~nm}$ emission filter for Cy2, and a $470 \pm 20 \mathrm{~nm}$ excitation filter, $510 \mathrm{~nm}$ dichroic mirror, and $520 \mathrm{~nm}$ emission filter for Alexa488. Images were obtained with a Spot II digital camera (Diagnostic Instruments, Sterling Heights MI, USA).

\section{Statistical analyses}

Experiments were repeated three times with separate OSE preparations. Results were analyzed by mixed-model analysis of variance (ANOVA), and Duncan's new multiple range test was used to compare means when overall significance was observed. Fas and FasL mRNA concentrations were log-transformed prior to statistical analysis to normalize variance.

\section{Results}

\section{Purified cultures of bovine OSEs}

Purified cultures of bovine OSEs were derived from OSEs obtained from the surface of bovine ovaries collected at an abattoir. Primary cultures consisted of patches of pure OSEs interspersed with areas of mixed cell types. Areas of pure OSEs, identified by their characteristic morphology, were selectively passed by trypsinization using cloning cylinders to obtain pure cultures of OSEs. Experiments described here were performed on unfrozen cultures passed three or four times. OSE cultures displayed typical cobblestoned morphology (Fig. 1A). Their identity as epithelial cells was confirmed by their expression of cytokeratin, as visualized by immunofluorescent staining (Fig. 1B).

\section{FasL induces death of OSEs under a variety of conditions}

Treatment of OSEs with FasL in the presence of serumcontaining growth medium (described in the Materials 
A

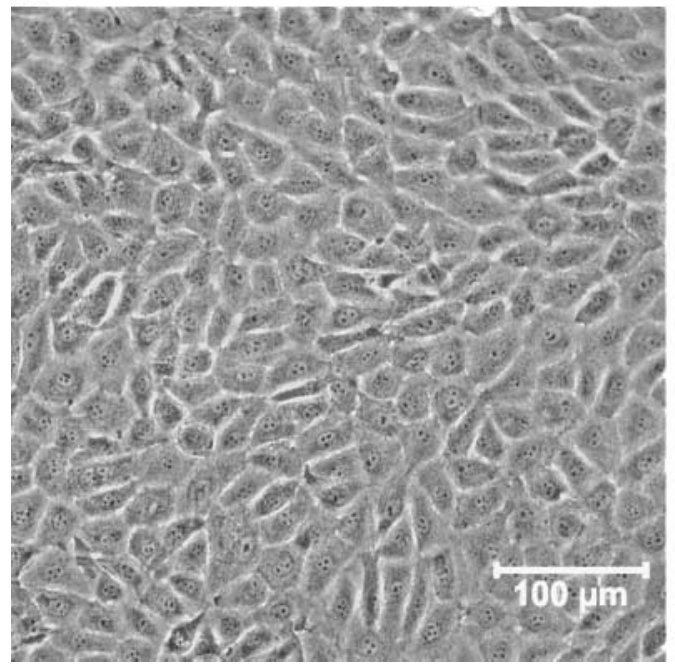

B

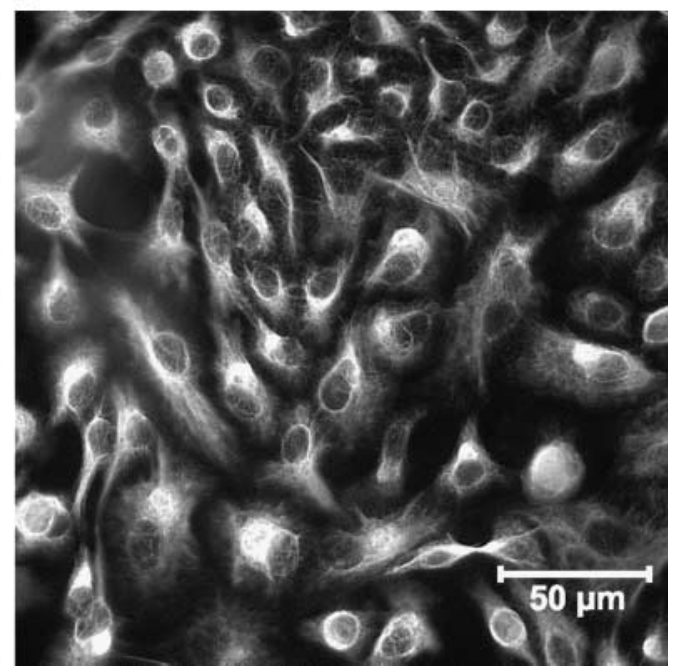

Figure 1 (A) Phase-contrast image of a typical bovine OSE culture. (B) Fluorescent immunocytochemical detection of cytokeratin in cultured OSEs.

and methods section) caused a $45 \pm 13 \%$ reduction in the number of viable cells (Fig. 2). As expected, the reduction in cell number was mediated by apoptosis since inhibition of caspase activity prevented cell death (see below). In minimal medium, consisting of DMEM/F12 plus antibiotics, the reduction in cell number in response to FasL was similar (43 $\pm 9 \%, P>0.05)$. Addition of IFN- $\gamma$ to each medium did not significantly alter the response to FasL: a $56 \pm 25 \%$ decrease in cell number in cells cultured in growth medium with IFN- $\gamma$, and a $58 \pm 16 \%$

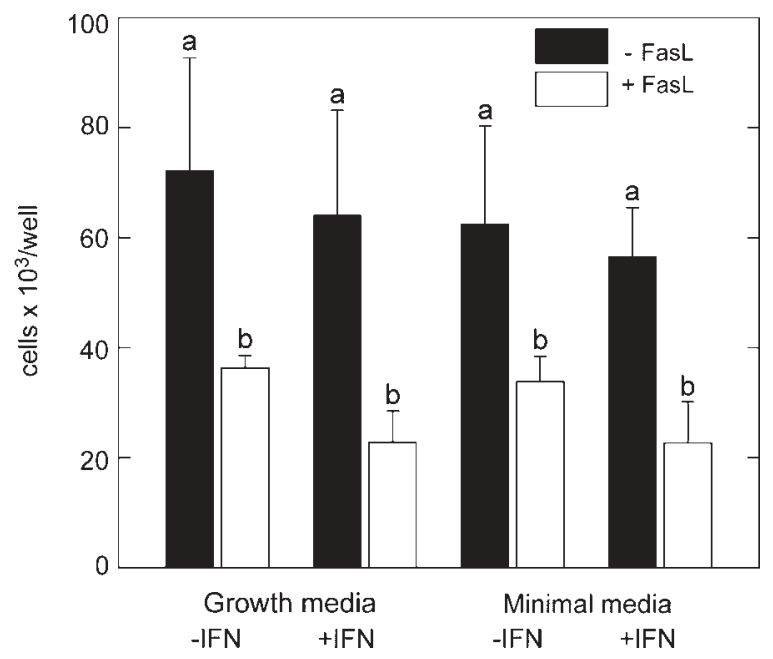

Figure 2 Effect of culture medium on FasL-induced death of OSEs. OSEs were grown to confluence and either maintained in serum-containing growth medium or changed to serum-free minimal medium. After $24 \mathrm{~h}$, cells were treated with 0 or $100 \mathrm{ng} / \mathrm{ml}$ FasL in the presence

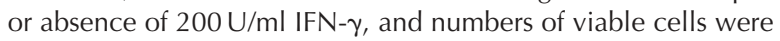
determined. Bars with different letters are significantly different $(P<0.05)$. Experiments were repeated with three separate cell preparations. reduction in cell number in cells cultured in minimal medium plus IFN- $\gamma$. There was no apparent reduction in cell number associated with removal of serum from medium, as illustrated by the similar number of viable cells in control wells (those not receiving FasL) in growth medium and minimal medium (Fig. 2). Subsequent experiments were performed in minimal medium.

\section{FasL, anisomycin, and daunorubicin induce apoptosis of OSES}

The effect of FasL, anisomycin and daunorubicin on apoptosis of OSEs was determined. OSEs were treated in the presence or absence of a broad-spectrum inhibitor of caspases, the peptide aldehyde known as ZVAD, to determine whether blocking major downstream effectors of apoptosis prevented cell death. The percentages of cell death in response to FasL, anisomycin, and daunorubicin were $36 \pm 6,62 \pm 6$, and $26 \pm 4 \%$, respectively (Fig. 3 ). In the presence of ZVAD, the percentages of cell death in response to FasL, anisomycin, and daunorubicin was reduced to $0 \pm 4,30 \pm 11$, and $6 \pm 3 \%$, respectively. Treatment with ZVAD alone had no effect on the number of viable cells.

\section{Anisomycin and daunorubicin increase expression of FasL, but not Fas}

The effects of anisomycin and daunorubicin on Fas and FasL mRNA and protein expression were analyzed by RTPCR and immunocytochemistry. Cells were treated with drugs in the presence of ZVAD to block apoptosis and allow measurement of changes in gene and protein expression. Expression of Fas mRNA was not altered in cells treated with anisomycin plus ZVAD or daunorubicin plus ZVAD compared with controls treated with or 


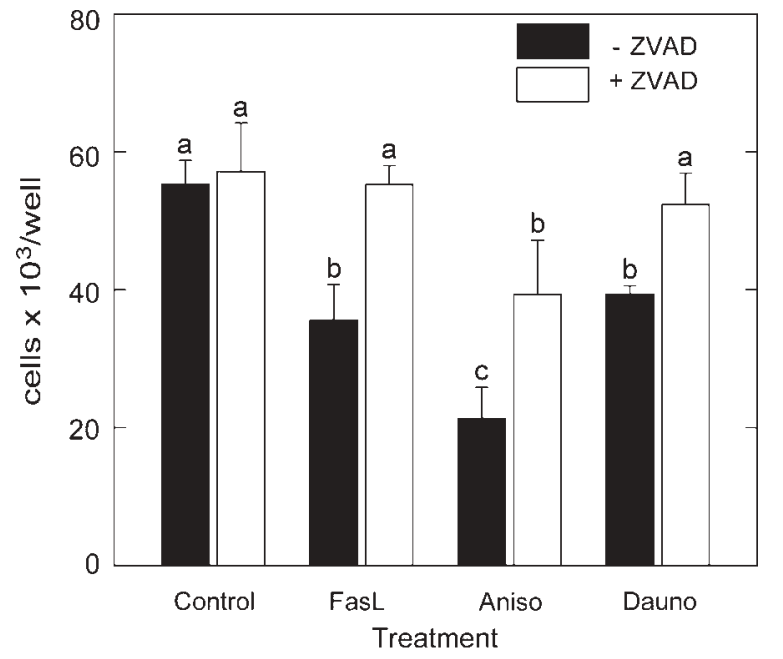

Figure 3 Inhibition of caspases reduces cell death in response to FasL, anisomycin (Aniso), and daunorubicin (Dauno). OSEs cultured in defined medium were given the following treatments in the presence or absence of $30 \mu \mathrm{M} Z \mathrm{ZVAD}$, a specific inhibitor of caspases: control, $100 \mathrm{ng} / \mathrm{ml}$ FasL, $2 \mu \mathrm{M}$ anisomycin, or $10 \mu \mathrm{M}$ daunorubicin. Numbers of viable cells were determined $24 \mathrm{~h}$ later. Bars with different letters are significantly different $(P<0.05)$. Experiments were repeated with three separate cell preparations.

without ZVAD (Fig. 4). However, FasL mRNA concentrations increased 3.1- and 2.5-fold in cells treated with anisomycin plus ZVAD and daunorubicin plus ZVAD, respectively (both $P<0.05$ versus controls). Treatment with anisomycin and daunorubicin had similar effects on expression of Fas and FasL proteins. Immunocytochemistry showed that Fas was detectable in control cultures with or without ZVAD, and was expressed at similar levels in cultures treated with anisomycin plus ZVAD and daunorubicin plus ZVAD (Fig. 5). In control cultures of OSEs, FasL protein was low to non-detectable. Treatment of OSEs with anisomycin plus ZVAD or daunorubicin plus ZVAD increased the intensity of staining for FasL (Fig. 5).

\section{Apoptosis of OSEs induced by anisomycin and daunorubicin is mediated by Fas signaling}

To determine whether apoptosis in response to anisomycin and daunorubicin is mediated by endogenous Fas-FasL interactions, OSEs were treated in the presence or absence of Fas:Fc, a recombinant hybrid protein consisting of the extracellular domain of Fas and an Fc domain of human immunoglobulin ( $\mathrm{Hu}$ et al. 2001). This soluble protein binds to FasL, preventing it from binding to cellular Fas and initiating Fas-mediated apoptosis. Addition of Fas:Fc to cultures of OSEs treated with anisomycin reduced cell death from $49 \pm 5$ to $30 \pm 3 \%(P<0.05$; Fig. 6). Similarly, addition of Fas:Fc to cultures of OSEs treated with daunorubicin reduced cell death from $27 \pm 1$ to $2 \pm 4 \%$ $(P<0.05)$. Treatment of control cultures with Fas:Fc had no effect on the number of viable cells.
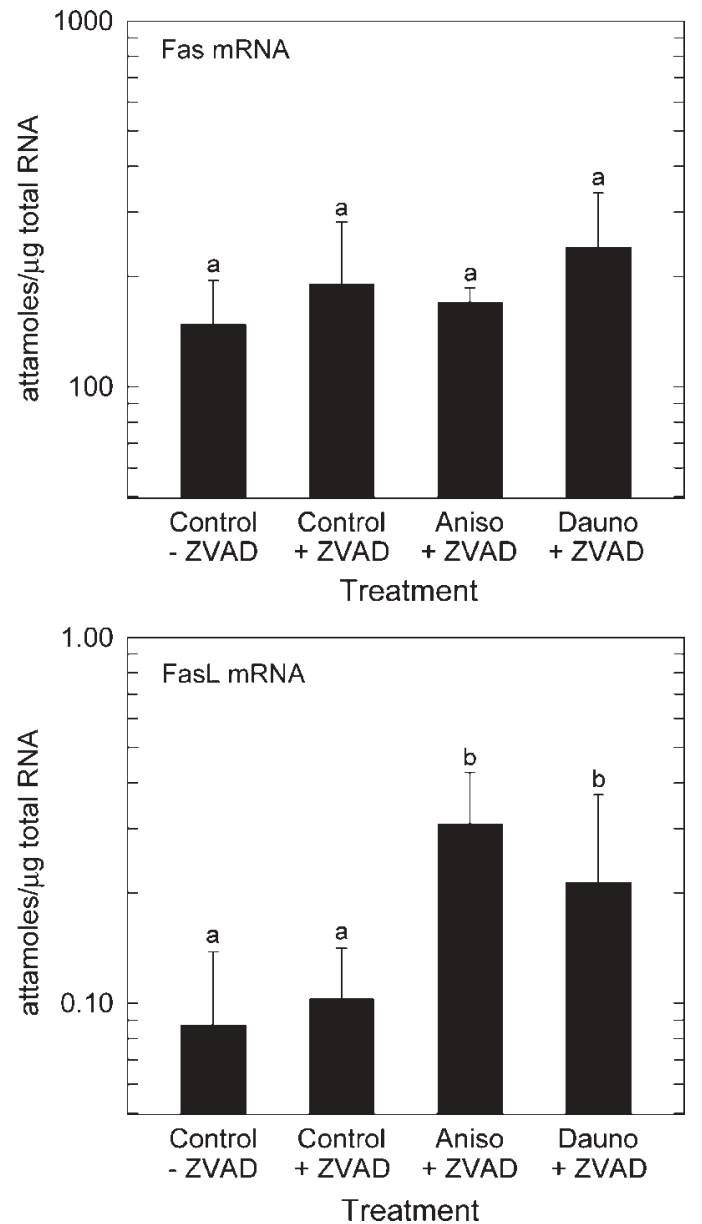

Figure 4 Expression of Fas and FasL mRNA by OSEs. OSEs in defined medium were given the following treatments: control without ZVAD, control $+30 \mu \mathrm{M}$ ZVAD, $2 \mu \mathrm{M}$ anisomycin (Aniso) $+30 \mu \mathrm{M} Z \mathrm{ZVAD}$, or $10 \mu \mathrm{M}$ daunorubicin (Dauno) $+30 \mu \mathrm{M}$ ZVAD. Cells were harvested $24 \mathrm{~h}$ later, RNA prepared, and quantitative RT-PCR for Fas and FasL performed. Bars with different letters are significantly different $(P<0.05)$. Experiments were repeated with three separate cell preparations.

\section{Discussion}

The results show that OSEs have an endogenous Fas pathway that is activated under conditions of stress. Initial experiments were performed to determine if bovine OSEs are susceptible to apoptosis in response to treatment with recombinant FasL and whether this is modulated by the conditions of culture. FasL-induced cell death was similar in OSEs cultured in serum-supplemented media and in defined media lacking serum. Addition of IFN- $\gamma$ did not alter the percentage of cells undergoing apoptosis in response to treatment with FasL. In previous experiments, mouse OSEs cultured in serum-containing medium were resistant to FasL-induced apoptosis unless they were co-treated with IFN- $\gamma$ (Quirk et al. 1997). Thus, bovine OSEs are more responsive than mouse OSEs to FasLinduced apoptosis in vitro in that they undergo apoptosis in the presence of serum and in the absence of co-treat- 

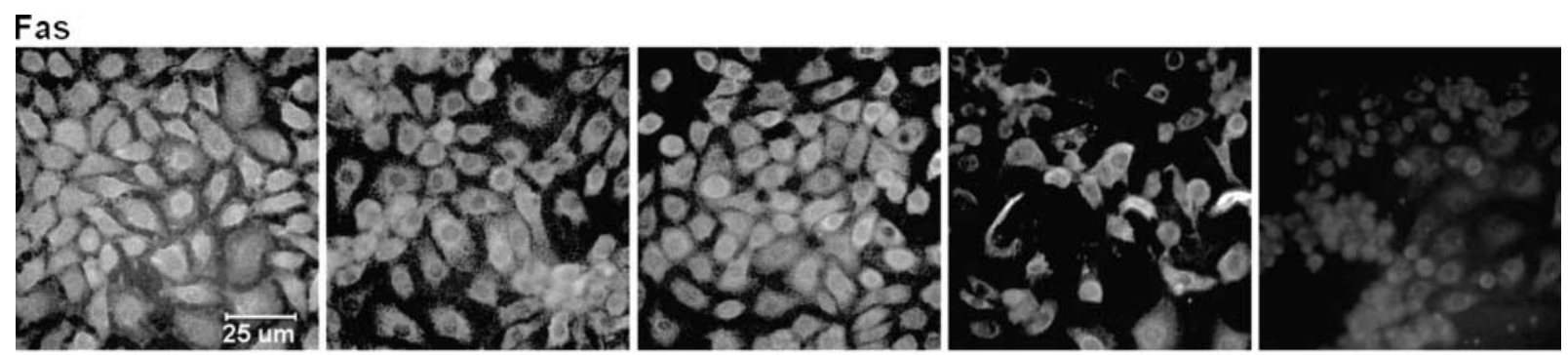

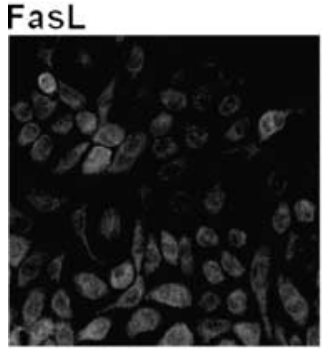

Control

- ZVAD

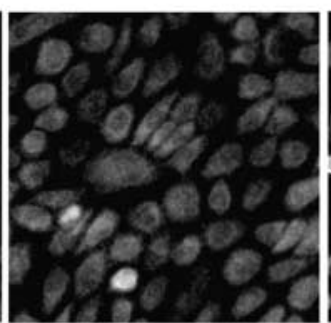

Control

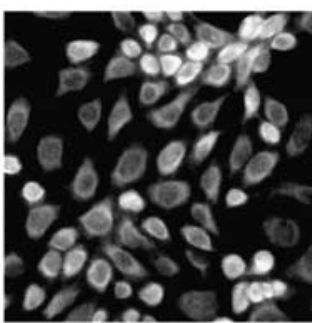

Aniso

+ ZVAD

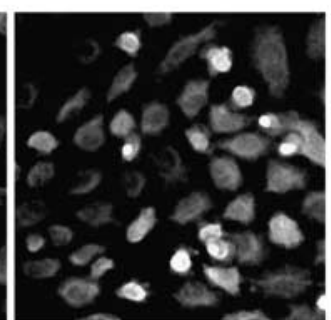

Dauno

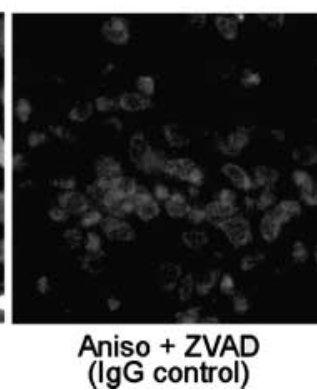

Figure 5 Expression of Fas and FasL protein by OSEs. OSEs in defined medium were given the treatments described in Fig. 4. Cells were fixed $24 \mathrm{~h}$ later, and immunocytochemical detection of Fas and FasL protein was performed. IgG controls were stained with IgG instead of specific antibodies. Experiments were repeated with three separate cell preparations.

ment with IFN- $\gamma$. The results of experiments with bovine OSEs also contrast with our findings in experiments with bovine granulosa cells; granulosa cells were susceptible to FasL-induced apoptosis in defined media lacking serum but were resistant in media containing serum unless IFN- $\gamma$ was provided as a co-treatment (Quirk et al. 2000). Furthermore, withdrawal of serum from culture media induced apoptosis of $50 \%$ of bovine granulosa cells within $24 \mathrm{~h}$ and this was mediated by endogenous Fas-FasL interactions (Hu et al. 2001). In contrast, bovine OSEs do

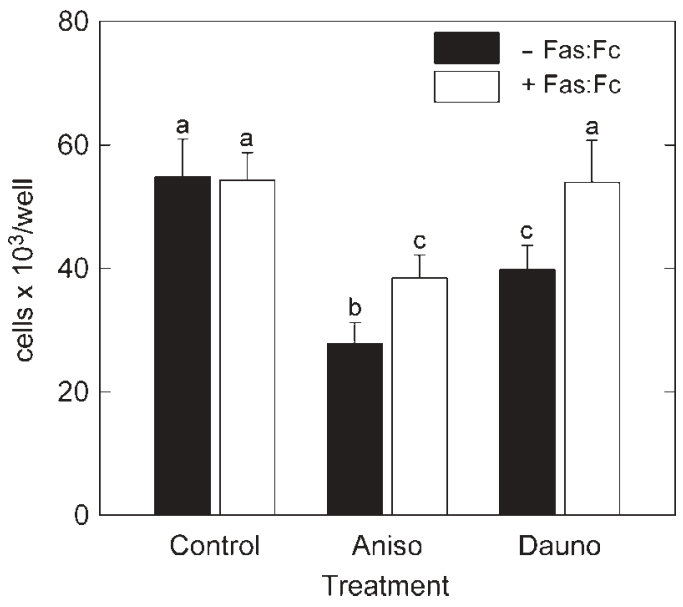

Figure 6 Apoptosis of OSEs induced by anisomycin and daunorubicin is mediated by endogenous Fas-FasL interaction. OSEs in defined medium were treated with medium (control), $2 \mu \mathrm{M}$ anisomycin (Aniso), or $10 \mu \mathrm{M}$ daunorubicin (Dauno) in the presence or absence of $20 \mu \mathrm{g} / \mathrm{ml} \mathrm{Fas:Fc,} \mathrm{a} \mathrm{specific} \mathrm{inhibitor} \mathrm{of} \mathrm{the} \mathrm{Fas} \mathrm{pathway.} \mathrm{Numbers}$ of viable cells were determined $24 \mathrm{~h}$ later. Bars with different letters are significantly different $(P<0.05)$. Experiments were repeated with three separate cell preparations. not undergo apoptosis when cultured in the absence of serum. Taken together, these studies indicate that factors regulating the susceptibility to Fas-mediated apoptosis within the ovary are cell-type specific.

In the current study, treatment with the drugs anisomycin and daunorubicin were used as a tool to determine whether bovine OSEs express FasL under conditions of cellular stress. Experiments with a number of cell types have shown that anisomycin, daunorubicin, and other drugs commonly used in cancer chemotherapy induce a stress response that involves expression of FasL and apoptosis through the Fas pathway (Friesen et al. 1996, Faris et al. 1998, Hsu et al. 1999). Anisomycin is a peptidyltransferase inhibitor that inhibits protein synthesis and activates JNK and p38 MAPK (Park et al. 1997, Shifrin \& Anderson 1999). JNK and p38 MAPK are involved in pathways that are stimulated in response to cellular stress and may mediate apoptosis (reviewed by Leppã \& Bohmann 1999). Daunorubicin also activates these pathways (Mansat-De Mas et al. 1999). In experiments reported here, treatment of OSEs with anisomycin or daunorubicin induced cell death, and cell death was inhibited by addition of the broad-spectrum caspase inhibitor, ZVAD (Slee et al. 1996). Caspases are cysteine proteases, activated downstream of a number of apoptotic stimuli, that target the cleavage of substrates essential for cell survival (reviewed by Hengartner 2000). The fact that ZVAD suppressed cell death in response to FasL, anisomycin, and daunorubicin demonstrates that, as expected, these agents induce apoptosis by activation of caspases. In this study, co-treatment of OSEs with ZVAD suppressed apoptosis in response to anisomycin and daunorubicin and allowed measurement of mRNA and immunoreactive protein for Fas and FasL in drug-treated 
cells. The fact that ZVAD only partially prevented the loss of viable cells in response to anisomycin (Fig. 3) indicates that anisomycin-induced cell death may occur by mechanisms in addition to apoptosis.

Quantitative RT-PCR and immunocytochemistry were used to test whether bovine OSEs have the ability to express Fas and FasL and whether the level of expression varies with physiological status. Under control culture conditions favorable to cell survival, OSEs expressed Fas mRNA and protein whereas FasL mRNA was detectable but FasL protein was low to non-detectable. Treatment of cells with anisomycin or daunorubicin in the presence of ZVAD increased FasL mRNA and protein. When cells were treated with anisomycin and daunorubicin in the absence of ZVAD, apoptosis was induced. Anisomycinand daunorubicin-induced apoptosis were reduced by treatment with Fas:Fc, a recombinant protein that blocks the interaction of Fas with FasL, indicating that apoptosis in response to drugs was mediated, at least partially, by endogenous Fas-FasL interactions. Whereas Fas:Fc completely prevented the loss of viable cells in response to daunorubicin, it only partially prevented the effect of anisomycin. Therefore, while the effect of daunorubicin may be mediated primarily through activation of the Fas pathway, the effect of anisomycin may be mediated only partially through Fas-FasL interaction. These results show that OSEs have an endogenous Fas pathway and that induction of FasL expression is a critical determinant of activation of the pathway. The fact that OSEs have a functional Fas pathway that becomes activated under conditions of cellular stress suggests the possibility that Fas-mediated apoptosis may play a role in ovulation. Ovulation is associated with apoptosis of OSEs at the site of follicle rupture and breakdown of the underlying extracellular matrix (Murdoch 1995, Murdoch \& McDonnel 2002). A number of epithelia, such as mammary epithelium, undergo apoptosis when survival signals from the extracellular matrix are removed (Wiesen \& Werb 2000). Interactions among growth factors produced by OSEs and by stroma underlying the OSEs are believed to be important in maintaining survival of OSEs (Parrott et al. 2000b). It is possible that loss of OSEs communication with the extracellular matrix and stroma and reduced blood flow into the stigma may induce cellular stress and activation of the Fas pathway. Interestingly, tumor necrosis factor, a protein that is related structurally and functionally to FasL, has been shown to play a role in apoptosis leading to follicular rupture at ovulation (Murdoch et al. 1997).

The results obtained with OSEs in the current study are consistent with findings in other cell types. In Jurkat T cells, stimulation of the JNK pathway by treatment with anisomycin induced FasL expression and cell death whereas interference with Fas-FasL interactions inhibited anisomycininduced apoptosis (Faris et al. 1998). Similarly, in immature $\mathrm{T}$ cells, engagement of the $\mathrm{T}$ cell receptor increased expression of Fas and FasL and Fas-FasL interaction was required for activation-induced cell death (Hsu et al. 1999).
Regulation of FasL expression has been studied previously in transformed human OSEs cell lines and in human ovarian cancer cell lines. Similar to what was observed in the current study in which primary cultures of bovine OSEs were treated with drugs, activation of JNK by cisplatin in a human ovarian cancer cell line stimulated transcription of FasL and blocking FasL with a neutralizing FasL antibody inhibited cisplatin-induced apoptosis (Mansouri et al. 2003). Treatment with a gonadotropinreleasing hormone analog increased expression of FasL mRNA and protein in SK-OV-3 and CaOV-3 human ovarian cancer cell lines (Imai et al. 1998). In addition, steroids have been shown to alter FasL expression. FasL expression was non-detectable by Western blots of an immortalized human ovarian epithelial cell line, the Moody cell line, and of human neoplastic ovarian epithelial cells, the Hey cell line, but expression increased and was detectable after treatment with estradiol (Sapi et al. 2002). Treatment of a human OSE cell line, HOSE, and a malignant human ovarian cancer cell line, OVCA, with progesterone enhanced levels of FasL mRNA and protein in HOSE and lowered levels in OVCA (Syed \& Ho 2003). Finally, Fas and FasL protein were detectable by immunocytochemistry in ovarian epithelial tumors as well as in OSEs of normal ovaries (Van Haaften-Day et al. 2003). These studies indicate that, as in normal bovine OSEs, transformed OSE cell lines and ovarian epithelial cancer cell lines can be induced to express FasL by various treatments. A number of studies have described human ovarian cancer cell lines that differ from normal OSEs in being resistant to Fas-mediated apoptosis (Morimoto et al. 1993, Wakahara et al. 1997, Garban \& Bonavida 1999). One study demonstrated that differences in the susceptibility of ovarian cancer cell lines to Fas-mediated apoptosis were not related directly to the levels of Fas protein expression (Baldwin et al. 1999). Similarly, resistance of an ovarian cancer cell line to cisplatininduced apoptosis was not associated with differences in expression of Fas (Schneiderman et al. 1999). Instead, resistance was associated with failure of cisplatin to induce expression of FasL protein.

In summary, primary cultures of OSEs are susceptible to apoptosis in response to treatment with exogenous FasL. Under culture conditions that support cell survival, OSEs express Fas but little or no FasL. OSEs respond to cellular stress by increasing expression of FasL, which results in apoptotic cell death mediated by Fas.

\section{Acknowledgements}

This work was supported by National Institute of Health grant HO32535. The author's declare that there is no conflict of interest that would prejudice the impartiality of this scientific work.

\section{References}

Baldwin RL, Tran H \& Karlan BY 1999 Primary ovarian cancer cultures are resistant to Fas-mediated apoptosis. Gynecologic Oncology $74265-271$. 
Chomczynski P \& Sacchi N 1987 Single-step method of RNA isolation by acid guanidinium thiocyanate-phenol-chloroform extraction. Analytical Biochemistry 162 156-159.

Doraiswamy V, Parrott JA \& Skinner MK 2000 Expression and action of transforming growth factor alpha in normal ovarian surface epithelium and ovarian cancer. Biology of Reproduction 63 789-796.

Faris M, Kokot N, Latinis K, Kasibhatla S, Green DR, Koretzky GA \& Nel A 1998 The c-jun n-terminal kinase cascade plays a role in stress-induced apoptosis in Jurkat cells by upregulating Fas ligand expression. Journal of Immunology 160 134-144.

Friesen C, Herr I, Krammer PH \& Debatin K-M 1996 Involvement of the CD95 (APO-1/Fas) receptor/ligand system in drug-induced apoptosis in leukemia cells. Nature Medicine 2 574-577.

Garban HJ \& Bonavida B 1999 Nitric oxide sensitizes ovarian tumor cells to Fas-induced apoptosis. Gynecologic Oncology 73 257-264.

Hengartner MO 2000 The biochemistry of apoptosis. Nature $\mathbf{4 0 7}$ 770-776.

Hsu S-C, Gavrilin MA, Tsai M-H, Han J \& Lai M-Z 1999 p38 mitogen-activated protein kinase is involved in Fas ligand expression. Journal of Biological Chemistry 274 25769-25776.

Hu C-L, Cowan RG, Harman RM, Porter DA \& Quirk SM 2001 Apoptosis of bovine granulosa cells after serum withdrawal is mediated by Fas antigen (CD95) and Fas ligand. Biology of Reproduction 64 518-526.

Imai A, Tagaki A, Horibe S, Takagi H \& Tamaya T 1998 Evidence for tight coupling of gonadotropin-releasing hormone receptor to stimulated Fas ligand expression in reproductive tract tumors: possible mechanism for hormonal control of apoptotic cell death. Journal of Clinical Endocrinology and Metabolism 83 427-431.

Leppã S \& Bohmann D 1999 Diverse functions of JNK signaling and C-Jun in stress response and apoptosis. Oncogene 18 6158-6162.

Mansat-De Mas V, Bezombes C, Quillet-Mary A, Bettaïeb A, De Thonel D'orgeix A, Laurent G \& Jaffrézou J-P 1999 Implication of radical oxygen species in ceramide generation, c-Jun $\mathrm{N}$-terminal kinase activation and apoptosis induced by daunorubicin. Molecular Pharmacology 56 867-874.

Mansouri A, Ridgway LD, Korapati AL, Zhang Q, Tian L, Wang Y et al. 2003 Sustained activation of JNK/p38 MAPK pathways in response to cisplatin leads to Fas ligand induction and cell death in ovarian carcinoma cells. Journal of Biological Chemistry 278 19245-19256.

Morimoto H, Yonehara S \& Bonavida B 1993 Overcoming tumor necrosis factor and drug resistance of human tumor cell lines by combination treatment with anti-Fas antibody and drugs or toxins. Cancer Research 53 2591-2596.

Murdoch WJ 1995 Programmed cell death in preovulatory ovine follicles. Biology of Reproduction 53 8-12.

Murdoch WJ, Colgin DC \& Ellis JA 1997 Role of tumor necrosis factor- $\alpha$ in the ovulatory mechanism of ewes. Journal of Animal Science 75 1601-1605.

Murdoch WJ \& McDonnel AC 2002 Roles of the ovarian surface epithelium in ovulation and carcinogenesis. Reproduction 123 743-750.

Park J, Kim I, Oh YJ, Lee K, Han P-L \& Choi E-J 1997 Activation of c-Jun N-terminal kinase antagonizes an anti-apoptotic action of Bcl-2. Journal of Biological Chemistry 272 16725-16728.

Parrott JA, Kim G \& Skinner MK 2000a Expression and action of kit ligand/stem cell factor in normal human and bovine ovarian surface epithelium and ovarian cancer. Biology of Reproduction 62 1600-1609.

Parrott JA, Mosher R, Kim G \& Skinner MK 2000b Autocrine interactions of keratinocyte growth factor, hepatocyte growth factor, and kit-ligand in the regulation of normal ovarian surface epithelial cells. Endocrinology 141 2532-2539.
Parrott JA \& Skinner MK 2000 Expression and action of hepatocyte growth factor in human and bovine normal ovarian surface epithelium and ovarian cancer. Biology of Reproduction 62 491-500.

Porter DA, Vickers SL, Cowan RG, Huber SC \& Quirk SM 2000 Expression and function of Fas antigen vary in bovine granulosa and theca cells during ovarian follicular development and atresia. Biology of Reproduction 62 62-66.

Porter DA, Harman RM, Cowan RG \& Quirk SM 2001 Relationship of Fas ligand expression and atresia during bovine follicular development. Reproduction $121561-566$.

Quirk SM, Cowan RG \& Huber SH 1997 Fas antigen-mediated apoptosis of ovarian surface epithelial cells. Endocrinology $\mathbf{1 3 8}$ 4558-4566.

Quirk SM, Harman RM \& Cowan RG 2000 Regulation of Fas antigen (Fas, CD95)-mediated apoptosis of bovine granulosa cells by serum and growth factors. Biology of Reproduction 63 1278-1284.

Quirk SM, Cowan RG, Harman RM, Hu C-L \& Porter DA 2004 Ovarian follicular growth and atresia: the relationship between cell proliferation and survival. Journal of Animal Science $\mathbf{8 2}$ E40-E52.

Sapi E, Brown WD, Aschkenazi S, Lim C, Munoz A, Kacinski BM, Rutherford T \& Mor G 2002 Regulation of Fas ligand expression by estrogen in normal ovary. Journal of the Society for Gynecologic Investigation 9 243-250.

Schneiderman D, Kim J-M, Senterman M \& Tsang BK 1999 Sustained suppression of Fas ligand expression in cisplatin-resistant human ovarian epithelial cancer cells. Apoptosis 4 271-282.

Shifrin VI \& Anderson P 1999 Trichothecene mycotoxins trigger a ribotoxic stress response that activates c-Jun $\mathrm{N}$-terminal kinase and p38 mitogen-activated protein kinase and induces apoptosis. Journal of Biological Chemistry 274 13985-13992.

Slee EA, Zhu H, Chow SC, MacFarlane M, Nicholson DW \& Cohen GM 1996 Benzyloxycarbonyl-Val-Ala-Asp (OMe) fluoromethylketone (Z-VAD.FMK) inhibits apoptosis by blocking the processing of CPP32. Biochemical Journal 315 21-24.

Syed V \& Ho S-M 2003 Progesterone-induced apoptosis in immortalized normal and malignant human ovarian surface epithelial cells involves enhanced expression of FasL. Oncogene 22 6883-6890.

Talbot P, Martin GG \& Ashby H 1987 Formation of the rupture site in preovulatory hamster and mouse follicles: loss of the surface epithelium. Gamete Research 17 287-302.

Van Haaften-Day C, Russell P, Davies S, King NJC \& Tattersall MHN 2003 Expression of Fas and FasL in human serous ovarian epithelial tumors. Human Pathology 34 74-79.

Vickers SL, Cowan RG, Harman RM, Porter DA \& Quirk SM 2000 Expression and activity of the Fas antigen in bovine ovarian follicle cells. Biology of Reproduction 62 54-61.

Wakahara Y, Nawa A, Okamoto T, Hayakawa A, Kikkawa F, Suganama $\mathbf{N}$ et al. 1997 Combination effect of anti-Fas antibody and chemotherapeutic drugs in ovarian cancer cells in vitro. Oncology 54 48-54.

Wiesen J \& Werb Z 2000 Proteinases, cell cycle regulation, and apoptosis during mammary gland involution. Molecular Reproduction and Development 56 534-540.

Received 24 May 2005

First decision 4 July 2005

Accepted 16 August 2005 